\title{
SOCIAL SUPPORT PERCEPTION AND SUCCESSFUL AGING AMONG JAVANESE PEOPLE
}

\author{
Diah Karmiyati \\ The University of Muhammadiyah Malang \\ dkarmiyati@yahoo.com
}

\begin{abstract}
The objective of this research was to obtain a correlation between social support perception and successful aging among elderly Javanese people. This research was conducted by using quantitative correlational design. The method was intended to determine the contribution social support on successful aging. Subject of this research was the elderly whose the member of some elderly organization in Solo and Malang. The sampling technique used was purposive sampling based on the prescribed criteria of research subjects. Then, the collected data were then analyzed by using Pearson Correlation Method. The findings of this research showed that there was a significance positive correlation between social support perception and successful aging among Javanese people.
\end{abstract}

Keywords: successful aging, social support perception, Javanese people

\section{INTRODUCTION}

Successful Aging is a potential for elderly to keep on moving and active. According to Kimmel (1990) and (Rybash, et al (1991), elderly in their activities cover two things, i.e. which is related to social interaction and the other is productive behaviors. The increasing population of elderly is not always followed by the same success (successful aging) for all of them.

Based on the research of (Baltes, P.B; Freund, 2003), successful aging is a condition in which the elderly can choose, optimize, and compensate the drawbacks their experience. What is meant by choosing is to make a choice upon abilities they still possess in his/her old age. After making a selection and getting ability they possess, then, the old people will optimize it, develop this specific ability in accordance with his/her expectation and that of his surroundings. When needed, they can utilize certain compensation. The elder who cannot do these three things can be considered as unable to reach successful aging.
Studying elderly which is connected to culture will be very interesting. Culture as the determinant of human behavior has been acknowledged by common sense and empirical studies. Culture is the whole way of life descended down through generations in the forms of ritual, tradition, heritage, and behavior (Matsumoto, 2000). Culture is a set of programmed response since the beginning of time to make adjustment upon environment in the daily life and has become a software in mind.

In 2005, the research result done by Karmiyati shows that according to Javanese young people, successful elderly are those who live together with the family, useful, and still do social and religious activities. Furthermore, from the result of a research done by Karmiyati (2005) on farmer families, she concluded that a successful elderly are those who get married and their children is self-reliant. At the same time, they still can be productive and get involve in social activities in their community. 
In Japan, China, and South Africa, the family have responsibility in caring the elderly (Zheng et al, 2004) \& (Unanka, 2002). In the western countries, social support have a wider meaning. Social support not only from the family elderly but also from the social institution, especially which have responsibility of aging welfare.

Social support perception enjoyed by the elderly from their environment will surely be seen differently among old people. They can grasp it positively and negatively as well, depended on how they perceive it. The diverse perception on social support will affect whether or not successful aging can be achieved. Positive appreciation on social support will surely enable the elderly reaching successful aging, in their mind their surrounding still care for, respect, protect them, thus, they feel safe and comfortable. This positive perception can be formed because the elderly can feel that the place they live in is comfortable, a safe environment. Everybody does their own activities according to their own positions, there is a mutual respect. Elderly can also receive themselves fully and as-a-matter-offactly. This condition encourages the elderly to keep on building up useful activities in their old age. On the contrary, if the elderly perceive the social support negatively, they will feel threatened and unsafe, so they sense discouraged to extend and continue their useful activities in their old age, in short, fail to reach their successful aging.

Social support perception, together with human strengths and cultural values did not have significant correlation with successful aging (Karmiyati, 2005), so the objective of this research is to know a correlation between social support perception and successful aging partially.

\section{METHOD}

This research use corelational quantitative design. Corelation is referred to know the influence of free variables on depended variables. The dependent variable is successful aging that is a condition reflected by behaviors that can determine an ability possessed, developed optimally and applied it in their life. In expanding this skill, the elderly are willing to receive or ask for helps, as well employ aids when necessary. The independent variable is social support perception is the elderly's positive or negative views towards attention, empathy, help, love, and appreciation received from other people or those significant for them when in need.

The sampling technique in this research is purposive sampling, i.e. defining samples based on criteria, subjects being researched are in some elderly organizations in Solo and Malang. The researcher gave offers to each organization. From this offer, in Solo there are two organizations ready to join, and three in Malang. Data collection is done by using questionnaire and interview. The questionnaire is employed to get data on social support perception and successful aging. The interview is used to collect supporting data as complement to data obtained by questionnaire. The interview is guided in nature, meaning subjects are free to answer, as far as still on the track.

Data analysis use Partial Correlation Method by Pearson, to analize the correlation between two variables.

\section{Social Support Perception}

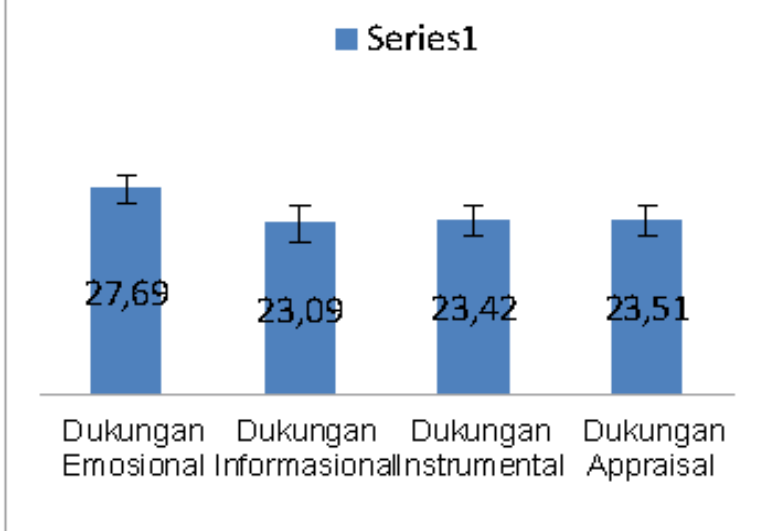

Figure 1. Aspects of Social Support Perception 
Emotional support to be the highest indicator to measure social support. It means that the elderly percept emotional support more than other three aspects, as Appraisal, instrumental, and informational support.

\section{Successful Aging}

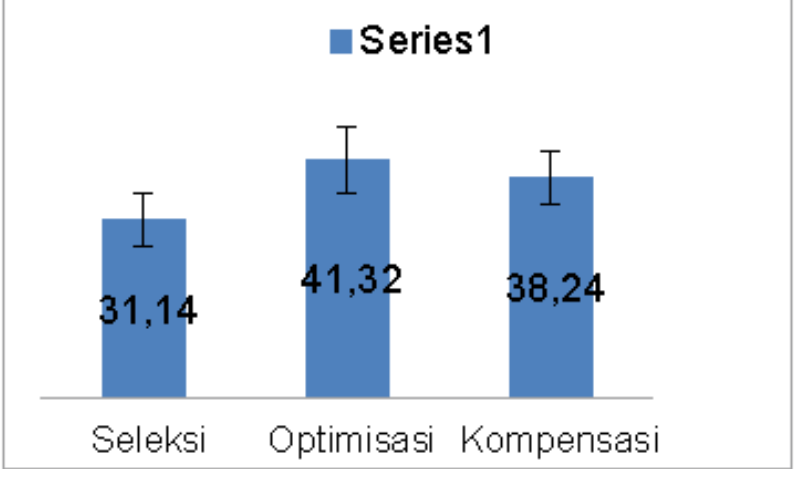

Figure 2. Aspects of Successful Aging

Optimization to be the highest indicator to measure successful aging. It means that optimization is the most thing do by the elderly more than two others.

Table 1. Correlations between Social Support Perception and Successful Aging

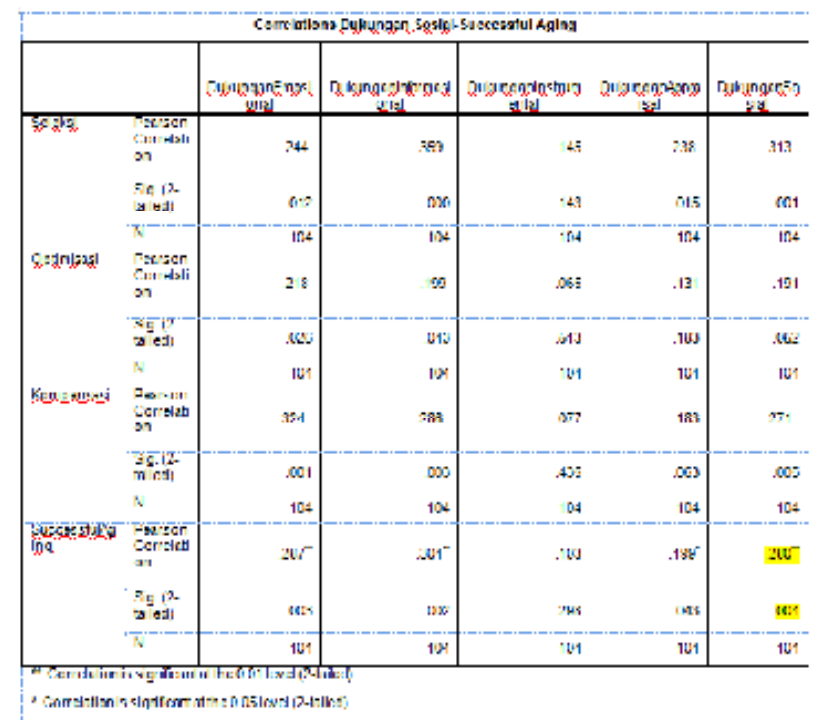

There is a positive and significant correlation between social support perception and successful aging. It means that if social support perception are high, and also the successful aging. On the contrary if social support perception to are low, and also the successful aging.

\section{DISCUSSION}

According to the results above there is correlation between social support perception and successful aging. The research result shows, either in Solo or Malang, the successful aging can be explained using social support perception.

On the previous research by (Karmiyati, 2005), found that there was no correlation between social support perception and elderly successful aging. From the result of the interview, in Malang as well as in Solo, the elderly consider the social support they receive from their family and peers not very important for them in doing their daily activities, i.e. the presence or absence of the social support does not keep them from cultivating the potentials they have, to be developed in their activities. The social support stated here is especially that related to financial or accommodation aids.

The elderly expect more of the emotional supports to cope with problems in their lives. This simply because the social support from the available institution has sufficed their needs, especially those related to health and social activities. This institution is like elderly local clinic, community elderly center, health clinic, and retirement organization. This does not mean the elderly give a negative perception on social support from their family, peers, or neighbors, it is more that this support does not directly or only vaguely affect the achievement of Successful Aging. The social support from their relatives will be more influential, for example, in discussing important matters in life like their children's wedding, finding jobs for their children, and sick treatment.

The preview research support by the result of this research that there was a connection and successful aging. The result of the preview research also found that emotional support more needed by the elderly more than other kind of 
support. Emotional support and caring are needed by the elderly when they are sick or when they want to decide an important thing about the whole family, for example to decide their son or daughter's wedding moment.

The limitation of this research is the subject characteristic only from retired people. It means that the demographic aspect, especially related to the background of education and financial income, they were financially independent. For that reason, to the next researchers advicely use subject from varied demographic background, in order to find varied result research.

\section{BIBLIOGRAPHY}

Baltes, P.B; Freund, A. M. (2003). Human Strengths as The Orchestration of Wisdom and Selective Optimization with Compensation. ((eds) In Aspinwall, L.G; Staudinger, U.M., Ed.). Washington DC: American Psychological Association.

Karmiyati, D. (2005). Successful Aging Lansia Indonesia. Malang.

Kimmel, D. (1990). Adulthood and Aging. Canada: John Wiley \& Sons Inc.

Matsumoto, D. (2000). Culture and Psychology: People Around the World. Belmont: Wadsworth, Thomson Learning.

Rybash, J. W; Roodin, P. A, Santrock, J. W. (1991). Adult Development and Aging. 2nd ed. New York: Wim C. Brown Publisher.

Unanka, G. O. (2002). Family Support and Health Status of The Elderly in Imo State of Nigeria. Journal of Sosial, 58(4).

Zheng, G; Liu, Y; Tang, H; Shi, S. (2004). Family Planning and The Value of Children in China. In Y. H. Setiadi, B. N; Supratiknya, A; Lonner, W. J; Poortinga (Ed.), Ongoing Themes in Psychology and Culture. International Association for Cross Cultural Psychology. 